\title{
AMBIGUITAS, INTERKULTURALITAS, DAN HIBRIDITAS RELASIONAL DALAM RELASI ANTARA ISRAEL DAN BANGSA-BANGSA LAIN
}

\author{
Robert Setio*
}

\begin{abstract}
Abstrak: Artikel ini merupakan analisis terhadap hubungan antara Israel dan bangsa-bangsa lainnya dengan menggunakan pemikiran tentang "liyan." Dalam masyarakat multikultural kehadiran liyan tidak terhindarkan dan menuntut tanggapan yang sungguh-sungguh. Keadaan ini pada gilirannya akan menciptakan ambiguitas, sebagaimana yang dialami oleh Israel. Penemuan arkeologis akhir-akhir ini membuktikan bahwa hubungan antara Israel dengan bangsa-bangsa lain ternyata tidak seperti yang dilukiskan oleh Alkitab. Israel bukanlah sebuah bangsa yang pada suatu masa datang ke Kanaan yang sudah berpenduduk, tetapi mereka muncul secara bertahap dari antara bangsa Kanaan sendiri. Maka, Israel memiliki banyak kesamaan dengan bangsa-bangsa lain itu. Pada pihak lain, Israel juga menumbuhkan sebuah ideologi yang lama-kelamaan akan membentuk mereka menjadi sebuah bangsa. Telah disarankan agar hubungan antara Israel dengan bangsa-bangsa lain itu dipandang sebagai hubungan interkultural. Meskipun pandangan itu masuk akal, namun penulis hendak mengajukan cara pandang lain. Cara pandang itu adalah hibriditas relasional. Dalam pandangan ini, Israel dilihat sebagai sebuah bangsa yang bersifat hibrid, namun bukan dalam arti yang statis. Hibriditas di sini dipandang sebagai sebuah keadaan yang menuntut tanggapan aktif. Dengan kata lain, kesamaan dan perbedaan antara Israel dengan bangsa-bangsa lainnya tidak boleh dianggap sebagai sebuah kondisi yang sudah jadi melainkan terus-menerus dalam proses pembentukan.
\end{abstract}

Kata-kata kunci: Liyan, ambiguitas, budaya, interkultural, agama, kesamaan, perbedaan, hibriditas relasional.

* Robert Setio, Fakultas Theologia, Universitas Kristen Duta Wacana, Jl. dr. Wahidin 5-22, Yogyakarta 55224. Email: robertsetio64@gmail.com. 


\begin{abstract}
This article will analyze the relationship between Israel and other nations using the concept of "the other." In a multicultural society, the presence of the other is unavoidable and demands a serious response. This, however, creates ambiguity, as experienced by Israel. Recent archeological findings have proven that the relationship between Israel and other nations mentioned in the Bible was unlike the description provided by the Bible. Israel was not a separate nation that came into an already occupied land of Canaan, but rather, it gradually emerged as a group from within the people of the land. Therefore, it can be expected that this nation shared many similarities with its cohabitants. On the other hand, it also developed a distinctive ideology which over time formed Israel as a separate nation. It has been suggested to consider the relationship between Israel and the others through the lens of interculturality. This article proposes another perspective, that is, a relational hybridity. From this perspective, Israel is seen as a hybrid nation. The hybridity is understood as a state of life, but, as one that always demands an active response. In other words, it is a process continously evolving.
\end{abstract}

Keywords: The other, ambiguity, intercultural, religion, similarity, difference, hybridity, relational

\title{
PENDAHULUAN
}

Kehadiran liyan (the other) dalam kehidupan bersama selalu memiliki fungsi ganda. Di satu pihak, ia berfungsi sebagai pembeda, di pihak lain, justru kebalikannya, ia mengingatkan tentang kesamaan-kesamaan. Sebagai pembeda, keberadaan liyan memberikan kepastian-kepastian yang dibutuhkan untuk pembentukan sebuah kelompok. Bahwa kelompok saya berbeda dari yang lain, itu dapat saya pastikan lewat keberadaan liyan. Akan tetapi kepastian-kepastian itu tidak mungkin dibiarkan terlalu padat sehingga sama sekali tidak ada celah untuk melihat kesamaan-kesamaan. Sebuah masyarakat yang normal pastilah terdiri dari kelompok-kelompok yang memiliki kesamaan, entah secara praktis ataupun dalam bentuk visi. Keberadaan liyan akan membuat kesamaan-kesamaan itu menjadi berarti, karena kesamaan yang ditemukan dari liyan akan lebih berkesan ketimbang kesamaan yang ditemukan pada kelompok sendiri. Dalam 
fungsinya yang ganda itu, kehadiran liyan sangat dibutuhkan oleh sebuah masyarakat.

Relasi antara Israel dengan bangsa-bangsa lain, yang hidup bersama atau bertetangga dengannya, memperlihatkan sebuah sikap terhadap liyan yang bersifat ganda itu. Bagi Israel, bangsa-bangsa lain itu adalah liyan yang ikut membentuk jati dirinya sebagai bangsa tersendiri. Israel menjadi Israel karena berbeda dari bangsa-bangsa lain, tetapi perbedaan itu bukanlah sesuatu yang sangat tertutup sehingga Israel sama sekali tidak memiliki kesamaan dengan bangsa-bangsa lainnya. Israel bukanlah makhluk aneh yang tidak bisa berkomunikasi dengan tetangga-tetangganya. Israel juga bukan bangsa yang begitu mandiri sehingga tidak pernah membutuhkan bantuan dari pihak lain. Gambaran Alkitab tentang Israel sebagai bangsa terpilih seakan membuat Israel terpisah dari bangsabangsa lain. Keterpisahan itu semakin dipertegas oleh pengertian "dikuduskan" yang berarti dipisahkan. Tetapi Alkitab juga mengisahkan bahwa dalam perjalanan hidupnya, Israel tidak terisolasi dari pergaulan dengan bangsa-bangsa lain. Israel juga pernah membutuhkan pertolongan bangsa lain. Hidup sebagai bangsa pilihan, yang berarti berada dalam perlindungan dari Tuhan, tidak membuat Israel memiliki kekuatan tanpa batas. Israel sama seperti manusia pada umumnya yang memiliki keterbatasan dan kelemahan. Ketika kelemahan itu muncul, Israel membutuhkan bangsa-bangsa lain.

Artikel ini akan memaparkan hubungan antara Israel dengan bangsabangsa lain dalam kerangka hubungan dengan liyan yang bersifat ganda tadi. Konsekuensi yang tidak terelakkan dari sifat ganda liyan adalah ambiguitas. Tulisan ini akan memperlihatkan ambiguitas baik yang ada dalam kisah-kisah Perjanjian Pertama sendiri, maupun dalam perbedaan antara bukti arkeologis-historis dan pernyataan-pernyataan dalam Alkitab mengenai Israel. ${ }^{1}$ Pada akhir tulisan ini akan dipertimbangkan pula

1 Penulis menggunakan istilah Perjanjian Pertama dan bukan Perjanjian Lama karena ingin memperlihatkan penghargaan terhadapnya. Meskipun Perjanjian Lama sudah terlanjur biasa digunakan oleh orang Kristen, namun tidak dapat dipungkiri bahwa istilah itu dahulunya dimaksudkan untuk memperlihatkan derajat yang lebih rendah, 
mengenai konsep yang lebih baik untuk melihat kesaksian Alkitab dan hasil-hasil penelitian arkeologi-sejarah: interkulturalitas atau hibriditas relasional. Keduanya mengungkapkan keragaman budaya, namun dengan cara yang berbeda. Perbedaan tersebut akan dibicarakan dalam bagian yang mengikuti pembicaraan mengenai ambiguitas hubungan antara Israel dan bangsa-bangsa lain.

\section{AMBIGUITAS DALAM PERJANJIAN PERTAMA}

Perjanjian Pertama melukiskan relasi Israel dengan bangsa-bangsa lain secara ambigu. ${ }^{2}$ Kisah mengenai nenek moyang Israel dalam Kitab Kejadian memperlihatkan bahwa para pendahulu bangsa Israel, seperti Abraham, Ishak, Yakub dan Yusuf, pernah mengalami pertolongan dari orang-orang asing. Ketika terjadi bencana kelaparan di negerinya, Abraham dan Ishak pergi mengungsi ke negeri tetangga untuk mendapatkan makanan yang mereka butuhkan. Dalam pelariannya-yang sekaligus merupakan pemenuhan permintaan ibunya untuk mencari isteriYakub pergi ke Haran, tempat ia mendapatkan isteri-isterinya. Ketika ia telah kembali ke Kanaan bersama dengan keluarga besarnya, dalam suatu kejadian yang sama seperti yang pernah menimpa ayah dan kakeknya, ia harus mengungsi karena bencana kelaparan yang menimpa negerinya. Yusuf yang kisahnya terkenal itu, lebih banyak menghabiskan waktu hidupnya di tanah Mesir di mana ia menjadi orang kepercayaan Firaun dan menjadi pejabat penting. Kisah para bapa bangsa Israel itu memberi pelajaran bahwa bangsa-bangsa lain bukanlah musuh yang harus dijauhi, melainkan kawan yang siap memberikan pertolongan dalam saat-saat sulit. Penulis kisah-kisah tersebut memiliki pandangan yang positif ter-

bahkan mungkin juga bermaksud merendahkan. Dalam kesadaran akan pluralisme agama-agama, penulis memilih untuk menghindari segala kesan yang merendahkan itu. Bagi penulis Perjanjian Pertama merupakan pilihan yang lebih baik jika kita ingin menghindari kesan merendahkan Alkitab yang asalnya adalah Alkitab Ibrani itu.

2 David Aaron menjelaskan ambiguitas dalam Alkitab merupakan akibat dari penggunaan bahasa figuratif terutama bila dikenakan pada Tuhan. Meskipun tulisan ini tidak memakai pendekatan bahasa seperti yang digunakan oleh Aaron, namun pengertian ambiguitas yang digunakan dalam tulisan ini dapat dikatakan sama yaitu sesuatu yang memiliki banyak kemungkinan makna. David H. Aaron, Biblical Ambiguities (Leiden-Boston-Koln: Brill, 2001), p. 1. 
hadap bangsa-bangsa lain. Pandangan tersebut tidak hendak disembunyikan sekalipun kisah-kisah tersebut memperlihatkan tentang sebuah hubungan yang khusus antara para bapa bangsa — dengan demikian seluruh bangsa Israel—dengan Tuhan.

Hubungan baik dengan bangsa-bangsa lain masih sering mewarnai kisah-kisah perjalanan hidup orang Israel setelah mereka keluar dari Mesir yang dilukiskan sebagai tanah perbudakan itu. Perjalanan menuju tanah Kanaan yang dijanjikan Tuhan untuk diberikan kepada Israel merupakan saat-saat yang sulit ketika Israel membutuhkan bantuan dari bangsabangsa yang negerinya mereka lewati. Perjanjian Pertama mencatat bahwa tidak semua orang yang negerinya dilalui Israel bersikap bersahabat dan bersedia memberikan pertolongan. Tetapi pastilah perjalanan yang pada akhirnya berhasil itu tidak mungkin terjadi tanpa pertolongan bangsa lain sama sekali. Walaupun kisah-kisah tentang perlakuan yang buruk dari bangsa-bangsa lain kepada Israel sangat menonjol, namun Alkitab tetap mengungkapkan kisah-kisah tentang penerimaan yang baik dari bangsa-bangsa lain terhadap Israel yang sedang menempuh perjalanan ke tanah yang dijanjikan Tuhan bagi mereka.

Sikap yang jauh lebih kritis terhadap bangsa-bangsa lain baru nampak ketika Israel memasuki tanah Kanaan. Tanah ini sendiri bukanlah sebuah tanah yang kosong. Di situ sudah ada penduduk asli yang tinggal sebelum Israel datang. Tetapi keberadaan mereka di sana tidak disambut dengan gembira. Perjanjian Pertama memberikan laporan dari sudut pandang Israel, khususnya sari sudut pandang elit Israel yang tidak sejahtera dengan kehadiran bangsa-bangsa lain bersama dengan orang Israel. Tidak heran jika karena itu penilaian terhadap bangsa-bangsa lain cenderung negatif. Masa-masa awal ketika orang Israel baru menduduki tanah Kanaan adalah masa-masa yang penuh dengan ketegangan, permusuhan, bahkan kekerasan. Perang melawan para penduduk pribumi Kanaan dilakukan terus-menerus demi mendapatkan suatu tempat tinggal yang ideal bagi Israel, yaitu suatu negeri yang tidak hanya sejahtera, melainkan juga bebas dari kehadiran orang asing yang dianggap mengganggu. Kitab Yosua mempersaksikan terjadinya genosida-genosida terhadap penduduk 
Kanaan yang direstui oleh Tuhan. ${ }^{3}$ Kitab Hakim-hakim menggunakan alasan penindasan oleh bangsa asing sebagai dasar untuk meneruskan program-program penyingkiran bangsa asing. Pada masa Kerajaan, permusuhan terhadap bangsa asing masih terus berlanjut. Raja-raja Israel dan Yehuda dinilai berdasarkan kesetiaan mereka terhadap Yahweh, Allah Israel. Penilaian buruk dijatuhkan apabila mereka menyembah ilah bangsa lain. Dibandingkan dengan Yehuda, raja-raja Israel lebih sering melakukan pelanggaran semacam itu. Raja Yosia dan Hizkia mendapatkan pujian yang tinggi karena mereka melakukan gerakan pemurnian agama. Mereka membasmi peribadatan yang tidak berpusat pada Yahweh. Gambaran tentang bangsa asing dikaitkan dengan penyimpangan peribadatan. Kemurnian ibadah berarti tidak saja menjaga kesetiaan kepada Yahweh, tetapi juga peniadaan bangsa asing dari kehidupan bersama.

Terlepas dari gencarnya upaya-upaya pemusnahan etnis itu, bangsabangsa asing masih tetap hidup di tanah Kanaan bersama dengan bangsa Israel sampai dengan masa Kerajaan, bahkan sesudahnya. Bila bangsabangsa asing itu bisa tetap hidup, lolos dari upaya pemusnahan etnis oleh bangsa Israel, pastilah karena peperangan-peperangan melawan mereka tidaklah sedahsyat dan sepamungkas seperti yang dikesankan oleh Kitab Yosua dan Hakim-hakim. Perjanjian Pertama sendiri juga melaporkan terjadinya hubungan simbiosis antara Israel dengan bangsa-bangsa lain. Raja Daud yang memiliki tempat istimewa di hati orang Israel pernah bekerjasama dengan orang Yebus, penduduk asli Yerusalem, dan membiarkan mereka hidup berasama dengan rakyatnya. Para nabi, seperti Yeremia, menganjurkan agar Yehuda bekerjasama dengan Babel dari pada melakukan perlawanan (Yer. 27). Yesaya memuji-muji Kores, raja Persia, bahkan menempatkannya sebagai gembala umat Tuhan dan yang akan memulihkan Yerusalem (Yer. 44: 28); mesias dan juruselamat (Yer. 45: 1; 13). Pengharapan yang besar kepada Persia itu juga sangat mendominasi

3 Lawson Younger melakukan kajian terhadap kisah-kisah penaklukan dari Timur Tengah Kuna. Hasilnya, banyak kesamaan antara kisah-kisah itu dengan kisah penaklukan dalam Kitab Yosua, di antaranya, penaklukan itu dipandang sebagai tindakan yang direstui Tuhan. Lawson Younger, Ancient Conquest Accounts. Journal for the Study of the Old Testament Suplement Series 98 (Sheffield: Sheffield Academic Press, 1990). 
kitab-kitab Ezra dan Nehemia. Sementara kitab Daniel meyakinkan pembacanya bahwa sikap yang benar bukanlah memusuhi melainkan bekerja dengan setia dalam pengabdian kepada raja-raja asing. Hal senada juga ditampakkan oleh kitab Esther. Kitab Rut malah tidak menyangkal adanya percampuran darah Moab dari Daud. Kitab Yunus sudah banyak dikenal sebagai kitab yang menyindir sikap yang merendahkan atau anti terhadap orang asing.

Perbedaan persepsi tentang orang asing itu menimbulkan ambiguitas. Manakah yang benar: orang asing diterima sebagai sesama atau justru dianggap sebagai musuh? Lalu status "umat terpilih" yang disandangkan kepada Israel itu, apakah harus dimengerti sebagai keharusan untuk memisahkan diri dari bangsa lain ataukah tidak? Persoalan ini nampaknya tidak selesai dan tidak pernah akan selesai. Oleh karena itu, ambiguitas masih akan terus menyertai pemahaman mengenai siapa Israel itu.

Orang Kristen-yang mengambil Israel sebagai model keumatan mereka-juga berada dalam kondisi yang sama. Seperti Israel, orang Kristen juga memandang dirinya sebagai umat terpilih. Keterpisahan dari liyan menjadi syarat yang tidak dapat ditawar-tawar. Meskipun hidup bersama dalam sebuah masyarakat, orang Kristen diharuskan hidup dengan menjalankan kebiasaan-kebiasaan yang berbeda. Cara pandangyang dalam bahasa sekarang disebut diskriminatif_-itu tertanam dalam kesadaran orang Kristen. Anehnya, Perjanjian Baru banyak memberikan kritik terhadap sikap eksklusif orang Yahudi. Bagaimana bisa mereka mengkritik keeksklusivan orang Yahudi jika mereka sendiri juga eksklusif? Itulah ironi yang terjadi dari sejak jaman Perjanjian Baru hingga sekarang. Untunglah jika orang Kristen tidak satu suara mengenai hal itu. Demikian juga dengan Perjanjian Baru. Ayat-ayat yang menganjurkan sikap-sikap non-diskriminatif juga tercatat dalam Perjanjian Baru. Karena itu, sama dengan penggambaran tentang Israel dalam Perjanjian Pertama, gambaran orang Kristen dalam Perjanjian Baru juga ambigu.

Di luar teks persoalannya menjadi berbeda. Penelitian arkeologis mengenai kehidupan orang Israel memperlihatkan gambaran yang tidak 
seperti gambaran dalam Perjanjian Pertama. Kesamaan-kesamaan antara Israel dengan bangsa-bangsa lain justru lebih menonjol dari pada perbedaan-perbedaannya. Israel adalah bagian integral dari masyarakat Levant (wilayah yang meliputi Siria, Lebanon, Israel, Palestina, Yordania, Ciprus, dan Hatai/Turki selatan), tempat mereka hidup selama berabad-abad.

\section{KULTUR YANG SALING BERBAGI}

Sudah cukup lama para sarjana Perjanjian Pertama memperlihatkan kesamaan-kesamaan antara isi Perjanjian Pertama dengan mitos, legenda, saga, dan bentuk sastra lainnya serta berbagai sebutan dan penggambaran tentang Tuhan yang berasal dari bangsa-bangsa lain. Kesamaan-kesamaan itu menimbulkan pertanyaan tentang bagaimana pola hubungan antara Israel dan bangsa-bangsa lain. Jika Israel berbeda dari bangsa-bangsa lain, mengapa ada kesamaan-kesamaan itu. Akhir-akhir ini temuan-temuan arkeologis semakin menambah jumlah kesamaan tersebut sehingga muncullah sebuah teori baru mengenai asal muasal Israel. Salah seorang sarjana yang menganut the mixed multitude theory, Ann Killebrew, mengatakan: "Prior approaches to early Israel tended to interpret ethnic formation as a linear and evolutionary development. However, recent ethnographic, anthropological, and sociological research suggests that ethnicity is a complex process rooted in diverse antecedent groups that converge and diverge over time."

Soal bagaimana sebuah masyarakat yang bercampur itu pada akhirnya dapat melahirkan sebuah bangsa bukanlah soal yang alamiah belaka. Israel terbentuk dalam suatu proses penyatuan identitas yang dijalankan lewat cerita-cerita yang dikisahkan secara berulang-ulang mengenai para pahlawan yang kemudian menjadi pahlawan bangsa, dan mengenai hubungan dengan Yahweh yang eksklusif dan krisis serta pembebasan yang pernah dialami oleh para pendahulu. Di luar proses pembentukan identitas bersama itu, Killebrew melukiskan,

4 Ann Killebrew, Biblical Peoples and Ethnicity (Atlanta: Society of Biblical Literature, 2005), p. 184. 
Ancient Israel's mixed multitude is defined here as a collection of loosely organized and largely indigenous, tribal, and kin-based groups whose porous borders permitted penetration by smaller numbers from external groups. Although it is impossible to reconstruct with certainty the protohistory of Israel's origins, it most likely comprised diverse elements of Late Bronze Age society, namely, the rural Canaanite population, displaced peasants and pastoralists, and lawless capfru and Shasu. Fugitive or runaway Semitic slaves from New Kingdom Egypt may have joined this mixed multitude. Nonindigenous groups mentioned in the biblical narrative, including Midianites, Kenites, and Amalekites (the latter perhaps connected with the control of camel caravan trade routes between Arabia to Canaan) may also have formed an essential element. ${ }^{5}$

Kondisi masyarakat yang bercampur itu membuat Israel tidak mungkin hidup secara eksklusif, sekalipun dalam proses pembentukan identitasnya keeksklusivan itu sangat ditekankan. Terlepas dari klaim eksklusivitas tersebut, Israel adalah bagian yang integral dari sebuah masyarakat, yang kemudian oleh Perjanjian Pertama dinamai Kanaan. ${ }^{6}$ Masyarakat itu terdiri dari berbagai kelompok yang diikat oleh tali kekeluargaan. Dari berbagai kelompok keluarga, atau lebih baik marga, itulah kemudian terbentuk kelompok yang lebih besar. Tetapi ikatan kelompok yang lebih besar itu bersifat cair. Juga dari waktu ke waktu selalu ada orang-orang dari luar daerah yang bergabung dan tinggal bersama. Di tengah dinamika masyarakat di Palestina tersebut ada sebuah pengaruh besar dari luar yang tidak boleh dilupakan yaitu Mesir. Kejayaan Mesir di masa lampau merupakan penentu perjalanan sejarah bangsa-bangsa di Palestina. Ketika kekuasaan Mesir sedang besar-besarnya maka bangsabangsa di Palestina dan sekitarnya yang berhasil ditaklukkannya akan berada di bawah kontrolnya dan dengan demikian dipersatukan. Di lain waktu ketika Mesir lemah maka bangsa-bangsa itu akan berusaha untuk berdiri sendiri, sehingga masyarakat yang dahulunya satu akan terpecah-

5 Ann Killebrew, Biblical Peoples, p. 184.

6 Penamaan oleh Alkitab ini dipersoalkan oleh Keith Whitelam yang memandangnya sebagai upaya untuk menutup mulut terhadap suara bangsa Palestina. Lihat bukunya, The Invention of Ancient Israel, The Silencing of Palestinian History (London-New York: 1996, 2003). 
pecah menjadi banyak kelompok. Keadaan seperti itulah yang terjadi di sekitar abad ke-12 sampai ke-11 s.M. Di masa itulah Israel diperkirakan mulai terbentuk.

Besarnya pengaruh Mesir bagi bangsa-bangsa lain di sekitarnya itu tidak hanya dalam hal politik saja, melainkan juga sampai pada soal-soal budaya dan kepercayaan. Firaun Akhenaten yang hidup pada abad ke14 telah dinilai sebagai penganjur monoteisme-meskipun pengertiannya tidak boleh dianggap sama persis dengan pengertian monoteisme sekarang - karena dialah raja Mesir yang menyembah satu dewa saja, yaitu Aten. ${ }^{7}$ Kalau kemudian Israel juga memiliki kepercayaan monoteistik bukan tidak mungkin idenya diambil dari revolusi Akhenaten itu. Atau, bisa juga ide itu diinspirasikan oleh pandangan tentang Dewa Amun yang dianggap sebagai satu-satunya dewa, sedangkan dewa-dewa lainnya merupakan manifestasinya saja. ${ }^{8}$ Selain itu, tradisi kenabian juga merupakan tradisi yang sangat umum di wilayah Semit Barat di mana Israel menjadi bagiannya, ${ }^{9}$ sehingga jika Perjanjian Pertama menceritakan tradisi kenabian, kita tidak perlu memandangnya sebagai tradisi yang hanya ada di Israel saja. Menarik pula untuk disebutkan tentang nama-nama dewa yang tertera pada prasasti-prasasti yang berasal dari jaman Perunggu Tengah dan Akhir di Kanaan (sekitar 1600-1200 s.M.). Selain nama dewa Baal yang sering disebut, terdapat pula nama dewa El ${ }^{10} \mathrm{El}$ sendiri adalah dewa kepala dari Ugarit. Menurut Richard Hess, penampilan El memiliki kemiripan dengan Yahweh dalam Perjanjian Pertama, yaitu sebagai dewa yang sudah tua, pencipta yang bijaksana, penguasa dewan ilahi yang juga dijuluki dengan istilah yang ada dalam Perjanjian Pertama yaitu "anakanak Allah." El juga dilukiskan bertahta di atas sumber sungai-sungai.

7 Richard S. Hess mencatat apa yang dilakukan Akhenaten ini ternyata tidak diikuti oleh semua rakyatnya. Penyembahan politeistis tetap berjalan. Akhirnya, monoteisme yang dipelopori Akhenaten itu sirna seiring dengan perlawanan terhadap kekuasaan dinastinya yang berpusat di Amarna. Richard S. Hess, Israelite Religions (Grand Rapids: Baker Academic, 2007), p. 92.

8 Richard S. Hess, Israelite Religions, p. 92.

9 Richard S. Hess, Israelite Religions, pp. 90, 92.

10 Richard S. Hess, Israelite Religions, p. 93. 
Jika El dibandingkan dengan dewa-dewa lainnya maka perbedaannya adalah hanya El saja yang dapat memperanakkan dewa. Tetapi setelah menyampaikan penjelasan-penjelasan tentang El itu, Hess buru-buru mengatakan bahwa El tidak sama dengan Yahweh. Alasannya ia ambil dari pendapat John Day yang mengatakan bahwa penggambaran tentang Yahweh yang penuh dengan murka dan tampil dalam wujud badai tidak cocok dengan penggambaran tentang El yang lemah lembut. Secara lebih utuh John Day sendiri menjelaskan:

First, in the Ugaritic texts the god El is revealed to be wholly benevolent in nature, whereas Yahweh has a fierce as well as a kind side. Secondly, as T.N.D. Mettinger has rightly emphasized, the earliest evidence, such as that found in Judg. 5.4-5, associates Yahweh with the storm, which was not something with which El was connected at all. Rather, this is reminiscent of Baal. Thirdly, as for P.M. Cross's view that Yahweh was originally a part of El's cultic title, 'El who creates hosts' ('il duyahwl saba'dt), this is pure speculation. The formula in question is nowhere attested, whether inside or outside the Bible. Cross's reasons for thinking that yhwh sb't cannot simply mean 'Lord of hosts', namely, that a proper name should not appear in the construct, is incorrect. Further, hyh (hwh) is not attested in Hebrew in the hiphil ('cause to be', 'create'), though this is the case in Aramaic and Syriac. Yahweh in any case more likely means 'he is' (qal) rather than 'he causes to be/creates' (hiphil): to suppose otherwise requires emendation of the Hebrew text in Exod. 3.14 ('ehyeh, 'I am'), which explains the name Yahweh. I conclude, therefore, that El and Yahweh were originally distinct deities that became amalgamated. ${ }^{11}$

Bila Yahweh tidak sama dengan El dan kalaupun ada kemiripannya, hal itu hanya terjadi karena proses amalgamasi. Bagaimana dengan El dalam Perjanjian Pertama sendiri? Dengan nada pasti Day mengatakan: “... a plausible case can be made that several of the El epithets referred to in Genesis in connection with patriarchal religion do indeed derive from the worship of the Canaanite god El (El-Shaddai, El-Olam, El-Bethel, and possibly El-Elyon)."12 Jadi sebutan-sebutan yang dikenakan kepada El dalam Kitab Kejadian

11 John Day, Yahweh and the Gods and Goddesses of Canaan. Journal for the Study of the Old Testament Suplement Series 265 (Sheffield: Sheffield Academic Press, 2000, 2002), pp. $13 ; 14$.

12 John Day, Yahweh and the Gods, p. 16. 
itu sepenuhnya berasal dari peribadatan Kanaan, bukan merupakan ciptaan orang Israel sendiri. Lalu, bagaimana dengan sebutan Yahweh? Day mengatakan:

Most scholars who have written on the subject during recent decades support the idea that Yahweh had his origins outside the land of Israel to the south, in the area of Midian (cf. Judg. 5.4-5; Deut. 33.2; Hab. 3.3, 7) and there has been an increasing tendency to locate Mt Sinai and Kadesh in N.W. Arabia rather than the Sinai peninsula itself..$^{13}$

Dengan demikian kita dapat menyimpulkan bahwa nama-nama Allah dalam Perjanjian Pertama merupakan hasil serapan dari nama-nama Allah yang sudah ada terlebih dahulu sebelum Israel terbentuk. Bahkan setelah Israel terbentuk dan Perjanjian Pertama ditulis, jejak-jejak serapan itu masih tetap dapat dilihat.

Soal asal muasal nama dan sifat Allah yang bukan asli Israel itu sebenarnya bukanlah hal baru. Para sarjana Alkitab sudah mendeteksinya sejak abad ke-19. Kalau ada yang baru mengenai soal ini adalah temuantemuan arkeologis yang memberikan gambaran yang lebih persis mengenai asal muasal Allah Israel itu. Di samping itu, ada juga persoalan pema-haman mengenai pola keagamaan Israel yang perlu direvisi sehubungan dengan temuan-temuan arkeologis akhir-akhir ini. Beth LaRocca-Pitts menjelaskan dengan ringkas beberapa poin revisi itu, (1) $\mathrm{A}$ clearer under-standing of the doctrine of aniconism; (2) Challenges to the biblical claim of monolatry; dan (3) Challenges to the doctrine of cultic centralization. ${ }^{14}$

Untuk poin pertama LaRocca-Pitts menyodorkan bukti tentang penggunaan karya seni berupa benda yang terbuat dari besi, patung keramik, lukisan pada gerabah, ukiran gading, ukiran batu, dan simbolsimbol pada prasasti dalam peribadatan Israel, meskipun belum ada karya seni mengenai Allah Israel itu sendiri. Agama Israel kuno—sama seperti

13 John Day, Yahweh and the Gods, p. 15. Penekanan dari penulis.

14 Beth LaRocca-Pitts, "These Are Your Gods, O Israel: The Challenge of Reconstructing Israelite Religion Using Both Text and Archeology" in Between Text and Artifact, edited by Milton C. Moreland (Leiden-Boston: Brill, 2004), pp. 54, 55. 
agama-agama kuna di jamannya — mengenal juga penggunaan ikon-ikon. Untuk poin kedua yaitu monolatri, LaRocca-Pitts menyodorkan ditemukannya gambar-gambar mengenai dewa-dewi yang berasal dari jaman Israel kuno. Dari bukti-bukti itu nampak bahwa orang Israel memiliki banyak macam sesembahan. Alkitab sendiri berkali-kali menyebutkan soal itu, walaupun dengan nada menentang. Tetapi terlepas dari penentangan itu, sebenarnya penyembahan kepada macam-macam dewa dan dewi merupakan praktik yang umum dijalankan oleh orang Israel. Tentu saja mereka tetap menyembah Yahweh, tetapi Yahweh bukanlah satu-satunya Allah yang mereka sembah. Herbert Niehr menjelaskan fenomena kegamaan yang dinamainya politeisme itu begini,

As a rule, ancient Near Eastern religions were polytheistic, and the religions of Judah and Israel were no exception to this rule. Polytheistic conceptions of the divine cannot be understood merely as a collection of several gods and goddesses; rather, they are best interpreted as systems of ordered interaction within divine world, in which every god and goddess has a dominion for which he or she is responsible..$^{15}$

Sedangkan mengenai tempat penyembahan, jika Alkitab selalu ada keharusan untuk mensentralisasikan ibadah di Yerusalem saja, temuantemuan arkeologis membuktikan adanya kuil-kuil yang tersebar di Israel baik pada jaman sebelum maupun sesudah pembuangan. LaRocca-Pitts berkata:

Archaeology also makes clear that, although the centralization of worship in the Jerusalem temple is presented by the text as a hard and fast doctrine (particularly by the Deuteronomist, as in $1 \mathrm{Kgs}$ 12:25-33), other shrines continued to exist and were used both in preexilic and postexilic Israel, a fact also implied in the text (1 Kgs 14:21-24). The most famous preexilic shrine outside Jerusalem is found at Arad (see discussion below). In the postexilic era there was a famous Israelite shrine on the island of Elephantine that existed contemporaneously with the restored temple in Jerusalem. ${ }^{16}$

15 Herbert Niehr, “'Israelite' Religion and 'Canaanite' Religion” in Religious Diversity in Ancient Israel and Judah, edited by Fransesca Stavrakopoulou and John Barton (LondonNew York: T\&T Clark, 2010), p. 28.

16 LaRocca-Pitts, “These Are Your Gods,” p. 55. 
Temuan-temuan arkeologis yang berlawanan dengan klaim-klaim Perjanjian Pertama tersebut memberikan kesan adanya pemahaman tentang agama yang berbeda dari yang dilukiskan oleh Perjanjian Pertama. Para sarjana kemudian menyimpulkan bahwa agama seperti yang diwakili oleh Perjanjian Pertama adalah agama yang resmi, sedangkan agama yang diwakili oleh bukti-bukti arkeologi adalah agama rakyat yang sifatnya lebih terbuka. ${ }^{17}$

William G. Dever-dalam bukunya yang berjudul Did God Have A Wife-menyampaikan hasil penelitiannya mengenai apa yang disebutnya sebagai folk religion dari Israel kuno. ${ }^{18}$ Dever menemukan figur dewi Asyera yang sangat penting dalam mitologi Ugarit, namun secara agak aneh hanya digambarkan sebagai patung sesembahan yang tidak berdaya dalam Perjanjian Pertama. Asyera juga digambarkan sebagai isteri Baal oleh Perjanjian Pertama yang maksudnya mungkin adalah mengolok-olok Baal maupun Asyera itu sendiri. ${ }^{19}$ Dalam salah satu puisi Ugarit dilukiskan dewa El yang sedang duduk di tahtanya sambil mengantuk. Lalu ia melihat Asyera datang dari sebuah perjalanan yang panjang. Begitu melihat Asyera, El langsung tertawa, kemudian bangkit dan mempersilakan Asyera masuk ke dalam kamarnya serta menawarkan makanan penyegar. Dikatakan bahwa El (disebut Lembu) mabuk cinta. Asyera kemudian melahirkan dewa-dewa; karenanya, ia dijuluki "Ibu dari Para Dewa." Dever melihat kedudukan yang penting dari Asyera itu sebenarnya tidak hilang begitu saja dalam masyarakat Israel. Tetapi penulis Alkitab dengan sengaja menutupinya. Meskipun demikian, usaha itu tidak

17 Fransesca Stavrakopoulou mengkritik penggunaan dikotomi agama "resmi-populer" yang menurutnya berangkat dari perspektif Alkitab yang sudah tidak netral dalam memandang agama yang tidak sejalan dengannya. Tetapi ia tetap bisa menerimanya sejauh pemahamannya bukan yang satu (yang resmi) lebih sah dari pada yang lain (yang populer), melainkan yang satu (populer) mewakili agama rakyat, yang lain (resmi) mewakili agama negara atau nasional. [Fransesca Stavrakopoulou, "'Popular' Religion and 'Official' Religion: Practice, Perception, Portrayal" in Religious Diversity in Ancient Israel and Judah, edited by Fransesca Stavrakopoulou and John Barton (London-New York: T\&T Clark, 2010), pp. 37-42].

18 William G. Dever, Did Yahweh Have A Wife? (Michigan: Wm. B. Eerdmans Publications, Co., 2005).

19 Dikisahkan dalam kisah Ahab dan Isebel dalam 1Raj. 16: 32; 33. 
sepenuhnya berhasil. Dari kisah-kisah yang mengangkat Asyera, walaupun selalu disertai nada permusuhan, namun tetap memperlihatkan bagaimana penyembahan terhadap Asyera itu masih dijalankan oleh rakyat Israel. Hanya agama resmi saja yang melarangnya. ${ }^{20}$

\section{INTERKULTURALITAS}

Data mengenai pola keagamaan di Israel kuno di atas masih dapat ditambah dengan berbagai hasil studi yang dilakukan oleh para sarjana yang memanfaatkan temuan-temuan arkeologis, tetapi untuk keperluan membuka diskusi mengenai interkulturalitas dalam Perjanjian Pertama, keterangan yang diberikan tadi kiranya sudah cukup. Dari situ kita sudah memperoleh gambaran bahwa Israel bukanlah sebuah bangsa yang sudah ada secara utuh sejak semula. Apa yang oleh Alkitab disebut sebagai bangsa Israel, bila dikaji dari sudut arkeologis, lebih baik dipandang sebagai sekelompok orang yang hidup bersama di suatu daerah yang entah mau dinamakan Kanaan atau Palestina. Mereka hidup bersama dengan kelompok lain dalam suasana saling bergantung dan melengkapi. Kesatuan di antara mereka pun juga tidak selalu berada dalam sebuah kondisi. Oleh sebab itu, sulit untuk dikatakan bahwa secara budaya mereka itu berbeda.

Hasil-hasil penelitian mengenai hidup keagamaan Israel juga memperlihatkan keterkaitan yang erat antara Israel dan bangsa-bangsa lainnya. ${ }^{21}$ Pada akhirnya, kalaupun ada perbedaan, perbedaan itu adalah justru antara mereka yang menginginkan sebuah agama yang murni Israel dan mereka yang tidak memedulikan soal kemurnian itu. Kelompok yang terakhir ini justru merupakan kelompok mayoritas karena mereka berada di daerah-daerah (rural area) dan pola keagamaan mereka adalah yang

20 Dever menjelaskan kisah penyembelihan 450 nabi Baal oleh Elia dalam 1Raj. 18: 2040 tidak menyebutkan nasib 400 nabi Asyera yang sebenarnya saat itu turut dipanggil ke gunung Karmel (ay. 19). Itu berarti, nabi-nabi Asyera itu tidak ikut dibunuh; alasannya adalah karena keberadaan mereka tidak dianggap bermasalah. William G. Dever, Did Yahweh, p. $211 \mathrm{ff}$.

21 Para sarjana Perjanjian Pertama sudah lama mengenali nama-nama yang mirip dengan nama-nama sesembahan Israel. Kemungkinan Israel menyerap nama-nama itu dari bangsa-bangsa sekitarnya, meskipun penyerapan itu dilakukan dengan penyesuaianpenyesuaian. 
dipraktikkan di rumah tangga (household) masing-masing . Penelitian para sarjana akhir-akhir ini lebih terarah pada agama yang dipraktikkan di rumah-rumah tangga ini. ${ }^{22}$ Justru agama yang dipraktikkan di rumahrumah tangga itulah yang lebih mencerminkan kondisi keagamaan bangsa Israel yang sesungguhnya.

Sejauh tujuan kita adalah melihat budaya yang dihidupi oleh orang Israel kuno, maka gambaran yang semacam itulah yang akan kita dapatkan. Masalahnya adalah apakah dengan gambaran semacam itu kita akan dapat melihat terjadinya interkulturalitas? Rasanya bukan interkulturalitas yang terjadi, namun suatu budaya yang dihidupi bersama dengan segala dinamikanya. Lain halnya jika kita memandang dari sudut Perjanjian Pertama (yang dominan dan merupakan suara kaum Deuteronomis). Sebagaimana sudah penulis sebutkan di atas, Perjanjian Pertama memiliki pandangan yang berbeda. Israel dalam pandangan Perjanjian Pertama adalah sebuah bangsa yang berbeda, bahkan istimewa. Agama Israel juga sangat berbeda dari agama-agama lain di sekitarnya. Dengan pemosisian seperti itulah baru kita bisa membicarakan suatu proses interkulturasi, karena jelas ada yang namanya budaya Israel dan budaya bangsa-bangsa Kanaan lainnya. Tetapi kita sudah melihat bahwa pemosisian seperti itu problematik. Kecuali kita menerima bahwa agama yang diwakili Perjanjian Pertama bukanlah agama rakyat yang justru lebih banyak dianut, maka kita sulit untuk menerima penggambaran Perjanjian Pertama itu. Dengan kata lain, interkulturalitas baru terjadi ketika kehidupan agama yang sebenarnya cair justru dikentalkan untuk kemudian ditempatkan pada posisi tertentu di hadapan agama lain.

Pada bagian pendahuluan penulis menyebutkan tentang sifat ganda dari liyan. Sekarang penulis ingin mengatakan bahwa dalam pandangan interkulturalitas sifat ganda itu menjadi kabur. Yang ada adalah sebuah versi saja dari liyan, yaitu sebagai yang berbeda. Kesamaan-kesamaan antara liyan dan diri sendiri menjadi tidak penting atau malah tidak mau

22 Carol Meyers, "Household Religion" in Religious Diversity in Ancient Israel and Judah edited by Fransesca Stavrakopoulou and John Barton (London-New York: T\&T Clark, 2010), p. 119. 
diakui. Interkulturalitas mengandaikan adanya dua budaya yang berbeda yang kemudian dipertemukan atau dipersilangkan. Bila yang terjadi adalah suatu budaya yang bercampur maka sulit untuk dideteksi mana yang bertemu dengan mana. Dengan demikian sulit pula untuk menjalankan suatu proses interkulturasi.

\section{HIBRIDITAS YANG RELASIONAL}

Dalam artikel yang lain, penulis pernah menganjurkan agar kita melakukan telaah biografis untuk memahami kepelbagaian (hibriditas) yang membentuk diri kita. ${ }^{23}$ Usulan itu bersumber dari perjalanan hidup penulis sendiri yang sarat dengan percampuran budaya: keturunan Cina, dididik dalam keluarga Kristen yang separuh saleh separuh bebas, diajar sedikit-sedikit tentang ritual tradisional Cina, dan bertumbuh di lingkungan Muslim di kota Surabaya. Berdasarkan keyakinan bahwa orang yang seperti penulis tidak sedikit maka penulis memberanikan diri untuk mengajak orang lain melakukan proses analitis yang sama. Proses ini tidak sekadar menuntun kita kepada keasadaran akan hibriditas diri, melainkan juga untuk memahami bagaimana hibriditas itu sebenarnya merupakan sekumpulan relasi-relasi yang terus-menerus bergerak secara dinamis. Relasi-relasi itu menceritakan tentang sumbangan orang lain kepada penulis sekaligus juga sumbangan penulis bagi orang lain. Penulis menjadi dirinya karena orang lain dan karena apa yang ia berikan kepada orang lain. Ketika penulis menyadari tentang dirinya, yang ia lihat adalah relasi timbal balik itu. Percakapan dalam kesadaran diri sendiri itu terkadang harmonis, terkadang kritis, terkadang saling menerima, terkadang saling melawan, terkadang berakhir dengan sebuah sintesis, terkadang harus berakhir dengan sebuah antitesis. Di atas percakapan yang sinambung itu tidak ada kesimpulan tunggal yang dapat dibuat mengenai dirinya.

Sekarang penulis hendak mengusulkan agar telaah serupa dikenakan kepada Israel. Kehidupan Israel dapat kita lihat sebagai sebuah biografi. Bahan untuk membuat telaah biografis itu kita ambil dari Alkitab maupun

23 Lih. artikel penulis, “Biografi Sebagai Kontekstualisasi,” Jurnal Ledalero 11 (Juni 2012): 81-104. 
arkeologi-sejarah. Kedua sumber itu memang sering kali memberikan kesaksian yang berbeda mengenai Israel, tetapi perbedaan itu bukan soal ini atau itu. Israel bukanlah seperti yang dikisahkan Alkitab atau yang ditemukan oleh para ahli arkeologi-sejarah. Israel adalah sekaligus keduaduanya. Potret yang disodorkan Alkitab pada umumnya adalah tentang Israel yang elitis—ditambah jejak-jejak kaum non-elit-ataupun Israel yang resmi, sedangkan arkeologi-sejarah memberikan gambaran tentang Israel dalam lingkup rakyat atau rumah tangga. Di tengah perbedaanbahkan pertentangan dari sumber kesaksian itu — kita dapat memperoleh gambaran yang justru saling melengkapi. Bila dalam Alkitab agama rakyat, yang menurut istilah Niehr di atas bercorak politeistis itu ditempatkan sebagai praktik yang dicegah dan dilawan—dan karena itu Alkitab tidak terlalu bersemangat dalam mengungkapkannya atau malah hal itu diungkapkan dengan nada negatif-melalui penelitian arkeologis kita memperoleh gambaran yang lebih lengkap dan objektif tentangnya. Bila kita menghendaki sebuah gambaran mengenai peribadatan yang resmi, maka tidak perlu diragukan lagi bahwa sumber yang tepat adalah Alkitab. Lalu, apakah tujuan dari semua ini adalah untuk memperoleh gambaran yang lebih utuh mengenai Israel? Tentu saja keutuhan gambaran itu penting, namun itu semua bukanlah tujuan akhir dari proses yang mesti kita jalankan. Setelah mendapatkan gambaran yang lebih lengkap, kita masih perlu memikirkan apakah yang kiranya terjadi pada masyarakat Israel ketika ada dua macam pemikiran dan praktik keagamaan itu?

Meskipun belum ada cukup data mengenai pandangan penganut agama rakyat terhadap agama resmi, kita dapat membayangkan apa yang mungkin terjadi. Penganut agama rakyat-yang oleh Alkitab dianggap melanggar perintah Tuhan itu-akan tidak terlalu senang dengan tuduhan yang dilancarkan kepada mereka. Mereka sudah sewajarnya akan meno-lak tuduhan yang negatif itu. Mereka justru akan menganggap praktik yang mereka jalankan itulah yang benar. Setidaknya, mereka tidak merasa bahwa dengan menjalankan praktik keagamaan yang biasa mereka lakukan, mereka telah meninggalkan Yahweh. Nyatanya Yahweh memang tidak pernah absen dari peribadatan mereka. Yahweh hanya ditempatkan 
bukan sebagai satu-satunya sesembahan saja. Sekalipun sesembahan mereka bukan hanya Yahweh, mereka masih menempatkan Yahweh sebagai sesembahan yang paling tinggi tarafnya. Atau, setidaknya Yahweh dipandang sebagai sesembahan dengan fungsi tertentu sebagaimana sesembahan lainnya dengan fungsi lainnya pula. Pembagian fungsi di antara para sesembahan itu bukan hal yang aneh dalam masyarakat di Timur Tengah Kuno; bahkan bukan pula hal yang aneh bagi masyarakat sekarang.

Bila kita mengamati pola kehidupan beragama masyarakat yang dipraktikkan oleh masyarakat maka kita juga akan mendapati adanya semacam percampuran. Agama yang resmi bukan satu-satunya yang dijadikan pegangan. Ajaran Gereja, misalnya, sering kali bercampur dengan berbagai ajaran yang berasal dari luar Gereja. Seperti juga Alkitab, Gereja sering kali mengeluh tentang kurang setianya umat pada ajaranajaran pokok Gereja. Di mata Gereja, umat Kristen sering dipandang tidak menjalankan praktik keagamaan yang sebenarnya. Homili-homili menjadi ajang untuk meluruskan ajaran yang tidak benar itu. Yang masih menjadi pertanyaan adalah seberapa besar usaha pelurusan ajaran itu akan atau telah berhasil? Penulis sendiri menduga, kemungkinannya sangat kecil. Agama umat adalah seperti agama rakyat di Israel kuno. Agama seperti itu sifatnya cair, permisif, terbuka terhadap macam-macam ajaran di luar tradisi dan cenderung berpatokan pada tujuan. Praktik keagamaan semacam itu telah menuai kritik sebagai sinkretisme, pragmatisme, tidak mendalam dan sebagainya. Tetapi cap-cap negatif itu tetap tidak membuat agama rakyat beralih dari kebiasaan-kebiasaannya yang fleksibel itu.

Di sisi lain, agama resmi juga tidak henti-hentinya memberikan arahan, teguran bahkan gertakan agar umat kembali kepada ortodoksi. Umat yang mendapatkan arahan, teguran dan gertakan semacam itu pastilah memikirkan apa yang sebaiknya dilakukan. Kritik-kritik dari pemangku jabatan agama resmi sudah selayaknya membuat umat merasa bersalah. Di situlah terjadi benturan antara pemikiran umat dan pemikiran pejabat agama. Benturan itu memang tidak menyenangkan, namun tidak dapat dihindari dalam sebuah relasi yang masih terjalin. Bila hubungan 
antara umat dan pemimpin agama yang mewakili agama resmi masih terjadi, wajar jika di sana-sini terjadi benturan pandangan. Masalahnya adalah apakah benturan tersebut akan membawa perubahan? Kalau benar perubahan itu terjadi, maka siapa yang berubah? Penulis berharap, jawabannya adalah kedua belah pihak. Umat berubah, pemimpin umat juga berubah; tetapi perubahan itu tidak seharusnya sudah ditentukan dari awal. Perubahan itu hendaknya dibiarkan terjadi dalam sebuah kerelaan.

Sikap yang lebih terbuka terhadap bangsa lain—sebagaimana yang penulis paparkan pada bagian awal tulisan ini-kiranya mencerminkan terjadinya perubahan pandangan dari mereka yang semula berpegang teguh pada ortodoksi. Alkitab sebenarnya jujur terhadap perubahanperubahan itu, tetapi itu bukanlah suara yang dominan. Yang dominan justru yang konservatif. Bagaimana kita sendiri mesti menyikapinya? Hibriditas relasional tidak memilih sikap yang "atau ini atau itu" (eitheror), namun tidak juga yang "baik ini maupun itu" (both-and), dan "bukan ini, bukan itu" (neither-nor). Hibriditas relasional memilih untuk menempatkan ketegangan-ketegangan itu dalam sebuah kondisi yang terusmenerus begitu, dengan alasan bahwa ketegangan-ketegangan itu justru menyumbangkan energi yang diperlukan agar kehidupan dapat terus berlangsung. Agama justru akan terus hidup bila ketegangan-ketegangan yang terjadi di dalamnya terpelihara dengan baik. Begitu pula yang terjadi dengan bangsa Israel. Ketegangan antara agama rakyat dan agama resmi justru membuat Israel terus hidup bahkan sampai sekarang. Bila mengacu pada keadaan sekarang, ketegangan-ketegangan yang terjadi bukan sekadar antara Israel dengan Palestina dan bangsa-bangsa Arab di sekitarnya, namun juga antara orang-orang Israel sendiri. Soal Palestina adalah soal perbedaan pandangan antara orang Israel yang konservatif dengan yang terbuka, antara yang menolak hidup bersama dengan liyan dan yang dapat menerima liyan sebagai tetangga.

\section{PENUTUP}

Ambiguitas yang kita temui dalam penggambaran Alkitab tentang Israel merupakan cermin dari ketegangan antara Israel yang ideal dan 
Israel yang nyata, antara Israel yang murni dan Israel yang campuran, antara Israel yang eksklusif dan Israel yang pluralistik. Ketegangan itu tidak lain bersumber dari perbedaan pandangan yang dimiliki oleh kelompok elit yang mewakili agama resmi dan masyarakat pada umumnya yang mewakili agama rakyat.

Respon terhadap ketegangan tersebut dapat berupa interkulturalitas yang mengedepankan pertemuan dan persilangan antara dua budaya yang berbeda, dapat pula berupa hibriditas relasional yang melihat keragaman budaya sebagai kandungan dari suatu pribadi tertentu. Dalam pandangan yang terakhir, keragaman tidak dipandang sebagai sesuatu yang dari luar berhadapan dengan sesuatu yang dari dalam diri sendiri, melainkan sebagai sesuatu yang ada dalam diri sendiri. Jika demikian, soalnya bukan bagaimana kita bersikap terhadap pihak lain di luar diri kita, melainkan bagaimana kita bersikap terhadap diri kita sendiri yang ternyata tidak satu versi. Hibriditas relasional menganjurkan agar benturan pandangan yang sudah menjadi bagian dari diri sendiri itu tidak diakhiri dengan seleksi untuk mempertahankan yang satu dan mengeluarkan yang lain. Perbedaan pandangan itu justru didaku sebagai pembentuk diri sendiri. Cara paling baik untuk dapat menerima perbedaan itu sebagai bagian dari diri sendiri adalah dengan melakukan telaah biografis. Dalam hal ini, biografi tidak dibatasi hanya pada individu saja. Biografi dapat berupa biografi dari sebuah bangsa. Maka, bila fokus tulisan ini adalah Israel, biografinya adalah biografi Israel. Dari mana informasi mengenai biografi itu didapat? Sebagaimana yang sudah dipaparkan dalam tulisan ini, sumber informasi itu adalah Alkitab dan hasil-hasil penelitian arkeologi-sejarah.

\section{DAFTAR RUJUKAN}

Aaron, David H. Biblical Ambiguities. Leiden-Boston-Koln: Brill, 2001.

Day, John. Yahweh and the Gods and Goddesses of Canaan. Journal for the Study of the Old Testament Suplement Series 265. Sheffield: Sheffield Academic Press, 2000, 2006.

Dever, William G. Did Yahweh Have A Wife? Michigan: Wm. B. Eerdmans Publications, Co., 2005. 
Hess, Richard S. Israelite Religions. Grand Rapids: Baker Academic, 2007.

Killebrew, Ann. Biblical Peoples and Ethnicity. Atlanta: Society of Biblical Literature, 2005.

LaRocca-Pitts, Beth. "These Are Your Gods, O Israel: The Challenge of Reconstructing Israelite Religion Using Both Text and Archeology." In Between Text and Artifact, ed. Milton C. Moreland. Leiden-Boston: Brill, 2004, pp. 53 - 65.

Meyers, Carol. "Household Religion." In Religious Diversity in Ancient Israel and Judah, eds. Fransesca Stavrakopoulou and John Barton. LondonNew York: T\&T Clark, 2010, pp. 118 - 134.

Niehr, Herbert. "'Israelite' Religion and 'Canaanite' Religion." In Religious Diversity in Ancient Israel and Judah, eds. Fransesca Stavrakopoulou and John Barton. London-New York: T\&T Clark, 2010, pp. 23 - 36.

Setio, Robert. “Biografi Sebagai Kontekstualisasi." Jurnal Ledalero 11 (Juni 2012): 81-104.

Singgih, E.G. Dari Israel Ke Asia. Jakarta: BPK-Gunung Mulia, 1982.

- "Kherem in the Book of Deuternomy: God, War and Violence in the Old Testament." In Religion, Civil Society and Conflict in Indonesia, eds. Carl Sterkens, Muhammad Machasin, and Frans Wijesen. ZurichBerlin: LIT Verlag, 2009, pp. 41 - 57.

Stavrakopoulou, Fransesca. "'Popular' Religion and 'Official' Religion: Practice, Perception, Portrayal”. In Religious Diversity in Ancient Israel and Judah, eds. Fransesca Stavrakopoulou and John Barton. LondonNew York: T\&T Clark, 2010, pp. 37 - 58.

Ustorf, Werner. "The Cultural Origin of 'Intercultural' Theology." In Intercultural Theology, eds. Mark J. Cartledge and David Cheetham. London: SCM Press, 2011, pp. 11-28.

Whitelam, Keith W. The Invention of Ancient Israel, The Silencing of Palestinian History. London-New York: Routledge, 1996, 2003.

. "Problems in Reconstructing Background." In Oxford Handbook of Biblical Studies, eds. J.W. Rogerson dan Judith M. Lieu. Oxford: Oxford U.P., 2006, pp. 255 - 267.

Younger, Jr., K. Lawson. Ancient Conquest Accounts. Journal for the Study of the Old Testament Suplement Series 98. Sheffield: Sheffield Academic Press, 1990. 